\title{
Study on Efficient Heat Interchange Control in District Heating and Cooling System with Multiple Sub-plants
}

\author{
Hisataka Kitora ${ }^{1}$, Yasunori Akashi ${ }^{2}$, Jongyeon Lim $^{2}$ \\ ${ }^{1}$ The KANSAI ELECTRIC POWER CO., INC., Osaka, Japan \\ ${ }^{2}$ The University of Tokyo, Tokyo, Japan
}

\begin{abstract}
In order to cope with global environmental problems, district heating and cooling which enables energy saving not only for buildings alone but for entire districts, is effective, but it is necessary to analyze even the pressure distribution in the piping, since the transportation power increases. However, the current commercial simulation program does not have the ability so far, we created a simulation having the ability to target the actual plant. By utilizing this, conditions for promoting effective heat interchange between sub-plants in DHC system were investigated. This is beneficial when expanding DHC area.
\end{abstract}

\section{Introduction}

In recent years, it becomes an urgent issue to respond to environmental problems from global to city scale, such as global warming and heat island. In order to solve the problem, it is conceivable to effectively utilize energy not only in one building alone but in the whole area. District heating and cooling (DHC) has been considered as a solution to such problem. DHC plant is expanded with the development of the area, having sub-plants added. When DHC plant has multi sub-plants with performance differences, heat interchange between sub-plants can be one way to increase an energy efficiency of the overall plant. However, when the heat supply is bidirectional, it becomes a complex system and it is difficult to control a whole system. In the case of heat interchange between DHC sub-plants, because the heat conveying distance gets longer, larger conveying power of the secondary pump and the heat interchange pump is needed, and the influence of its behaviour on the system also increases. Therefore, it is indispensable to calculate the power considering the pump head and to grasp the pressure state in the pipe. In order to realize high efficiency operation of a whole plant, it is necessary to analyse the behaviour including control of heat source machines, conveying equipment (e.g., pumps and valves), and pressure distribution in the pipe. However, it is currently the commercial simulation program does not have the ability to do such calculations. Kobayashi (2012) built a simulation model corresponding to the operation optimization of the heat source system that can heat interchange, but when the heat source machine is operating, it is set as a model that requires a certain transportation auxiliary power. Nishiyama (2015) built a simulation model that calculate all the control states at beginning, and based on the resultant valve opening and
ON / OFF information of the equipment to calculate the flow rate, but it does not consider pressure distribution in piping. In this study, we have constructed simulation model with high reproducibility that can calculate the behavior of each heat source machine and conveying equipment, and conditions of pressure, flow rate and temperature in each pipe, and temperature condition inside the heat storage tank. We have conducted case studies using the simulation. In this paper, we discuss the effect of thermal load differences on demand sides and performance differences between plants on the effectiveness of the heat interchange.

\section{Target DHC system description}

The target system is a renewable energy utilization plant that uses river water as a heat source, and it consists of East Plant which started operation in 2012 and West Plant which started operation in the spring of 2017. Figure 1 is a map of the area. Both plants are adjacent to each other across the road, the building in the East area has a total floor space of approximately 146,000 square meters (application: office, commercial facilities, hall), the building in the West area has a total floor space of about $151,000 \mathrm{~m}^{2}$, (use: office, Commercial facilities, museum, hotel). Both plants need to be connected by piping according to the heat supply business law. These pipes allow chilled water and hot water to be exchanged between them. Table 1 lists the equipment specifications and Figure 2 is the system diagram of the chilled water and hot water system. Also, although the performance of the heat source equipment of both plants has a difference of 5 years at the completion time, there is no big difference. The East plant has two types of heat source machines: primary heat source machines (R-01, R-02, R03, R-04) connected to thermal storage tanks and secondary heat source machines (R-05, R-06) which supply chilled water directly to consumers. The heat

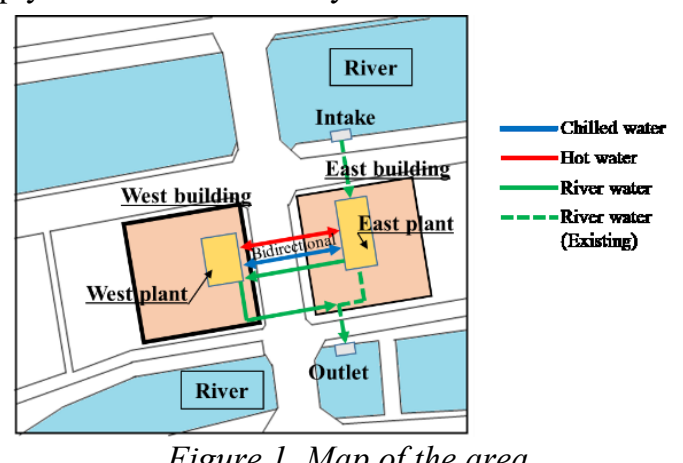

Figure 1. Map of the area 


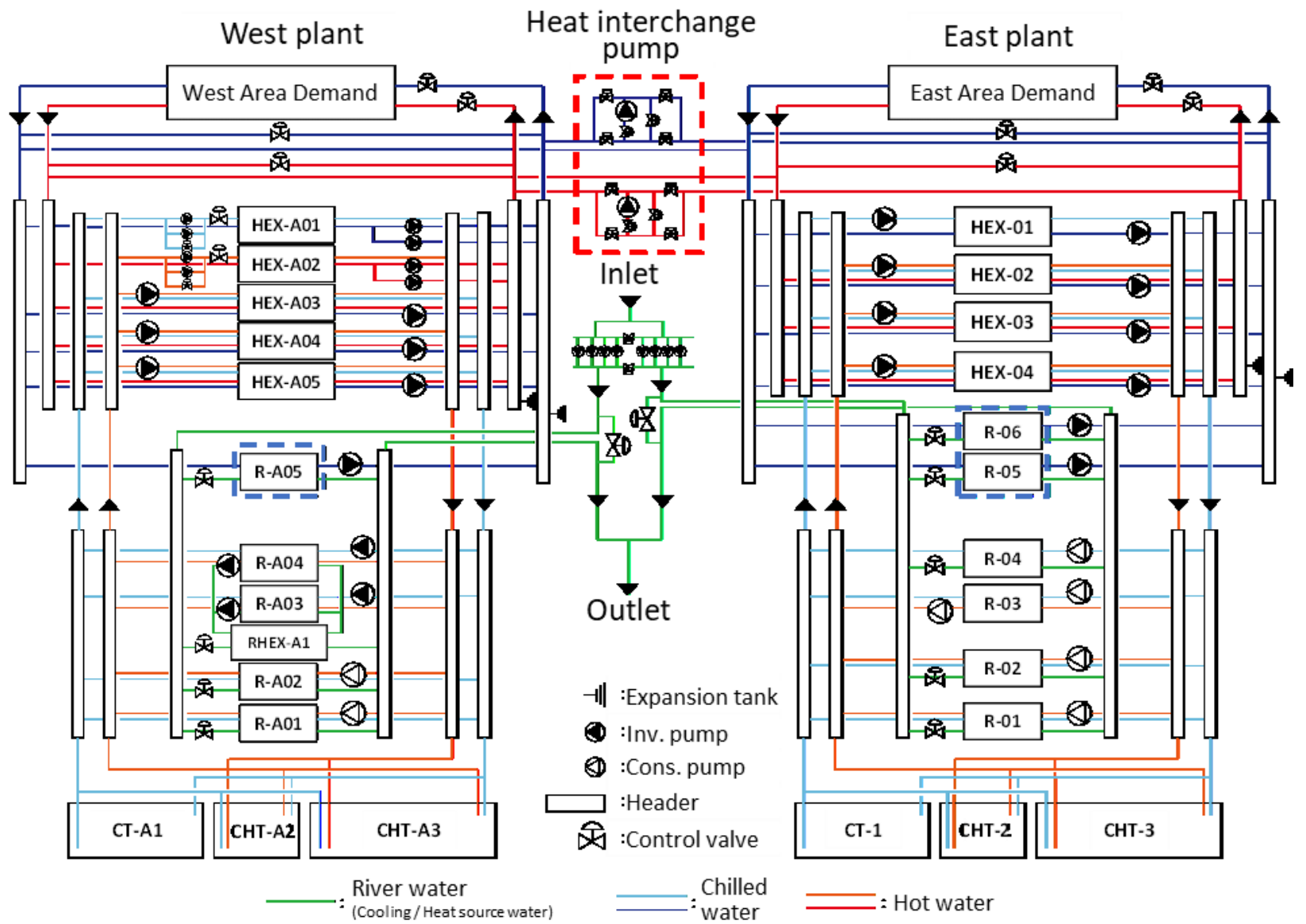

Figure.2 System diagram

Table .1 Equipment Specifications

\begin{tabular}{|c|c|c|c|c|c|}
\hline \multicolumn{6}{|c|}{ Performance of the West Plant equipment } \\
\hline No & Name & \multicolumn{2}{|c|}{ Performance } & Rating COP & Number \\
\hline \multirow{2}{*}{ R-A01, R-A02 } & \multirow{2}{*}{ Heat pump } & Cooling & $2750 \mathrm{~kW}$ & 5.10 & \multirow{2}{*}{2} \\
\hline & & Heating & $2800 \mathrm{~kW}$ & 5.13 & \\
\hline \multirow{2}{*}{ R-A03, R-A04 } & \multirow{2}{*}{$\begin{array}{l}\text { Heat recovery } \\
\text { heat pump }\end{array}$} & Cooling & $850 \mathrm{~kW}$ & Cooling 4.77 & \multirow{2}{*}{2} \\
\hline & & Heating & $1100 \mathrm{~kW}$ & $\begin{array}{c}\text { Heatung } 4.3 \prime \\
\text { Recov. } 7.74 \\
\end{array}$ & \\
\hline R-A05 & Turbo refrigerator & Cooling & $3200 \mathrm{~kW}$ & 5.88 & 1 \\
\hline R-HEXA1 & $\begin{array}{l}\text { Heat exchanger } \\
\text { (River water) }\end{array}$ & \begin{tabular}{|c|} 
Exchange \\
heat quantity
\end{tabular} & $1256 \mathrm{~kW}$ & - & 1 \\
\hline $\begin{array}{l}\text { HEX-A01, } \\
\text { HEX-A02 }\end{array}$ & $\begin{array}{l}\text { Heat exchanger } \\
\text { (For small load) }\end{array}$ & \begin{tabular}{|c|} 
Exchange \\
heat quantity
\end{tabular} & $1600 \mathrm{~kW}$ & - & 2 \\
\hline $\begin{array}{l}\text { HEX-A03,HEX- } \\
\text { A04,HEX-A05 }\end{array}$ & Heat exchanger & \begin{tabular}{|c|} 
Exchange \\
heat quantity
\end{tabular} & $3200 \mathrm{~kW}$ & - & 3 \\
\hline \multirow[b]{2}{*}{ CT-A1 } & \multirow[b]{2}{*}{$\begin{array}{l}\text { Heat storage tank } \\
\text { (Chilled water) }\end{array}$} & Capacity & $1050 \mathrm{~m}^{3}$ & - & \multirow[b]{2}{*}{1} \\
\hline & & $\begin{array}{c}\begin{array}{c}\text { Heat storage } \\
\text { amount }\end{array} \\
\end{array}$ & $10378 \mathrm{kWh}$ & - & \\
\hline \multirow[b]{2}{*}{ CHT-A2 } & \multirow{2}{*}{$\begin{array}{c}\text { Heat storage tank } \\
\text { (Chilled / Hot water) }\end{array}$} & Capacity & $650 \mathrm{~m}^{3}$ & - & \multirow[b]{2}{*}{1} \\
\hline & & \begin{tabular}{|c|}
$\begin{array}{c}\text { Heat storage } \\
\text { amount }\end{array}$ \\
\end{tabular} & $6424 \mathrm{kWh}$ & - & \\
\hline \multirow[b]{2}{*}{ CHT-A3 } & \multirow{2}{*}{$\begin{array}{l}\text { Heat storage tank } \\
\text { (Chilled / Hot water) }\end{array}$} & Capacity & $2000 \mathrm{~m}^{3}$ & - & \multirow[b]{2}{*}{1} \\
\hline & & $\begin{array}{c}\text { Heat storage } \\
\text { amount }\end{array}$ & $19767 \mathrm{kWh}$ & - & \\
\hline
\end{tabular}

source machines are controlled to supply heat from the thermal storage tanks during the day (07:00-22:00) and store heat in the tanks during the night (22:00-07:00). Calculate the amount of heat storage / release required to complete heat storage / release from a certain time to heat storage / release ending time (Recalculate the required heat every 30 minutes). Add / subtract the amount of heat required for heat storage / release from the heat load of the customer to calculate the amount of heat that the heat source machine shares. From this amount of heat, set the number of operation machine that the heat source machine can operate at the rated point. By these, the

\begin{tabular}{|c|c|c|c|c|c|}
\hline \multicolumn{6}{|c|}{ Performance of the East Plant equipment } \\
\hline No & Name & \multicolumn{2}{|c|}{ Performance } & Rating COP & Number \\
\hline \multirow{2}{*}{ R-01, R-02 } & \multirow{2}{*}{ Heat pump } & Cooling & $1760 \mathrm{~kW}$ & 5.0 & 2 \\
\hline & & Heating & $2000 \mathrm{~kW}$ & 5.0 & \\
\hline \multirow{2}{*}{$\mathrm{R}-03$} & \multirow{2}{*}{$\begin{array}{l}\text { Heat recovery } \\
\text { heat pump }\end{array}$} & Cooling & $340 \mathrm{~kW}$ & \multirow{2}{*}{$\begin{array}{r}\text { Recov. } \\
7.97\end{array}$} & \multirow{2}{*}{1} \\
\hline & & Heating & $450 \mathrm{~kW}$ & & \\
\hline $\mathrm{R}-04$ & Inv. Turbo refrigerator & Cooling & $1410 \mathrm{~kW}$ & 5.23 & 1 \\
\hline $\mathrm{R}-05, \mathrm{R}-06$ & Turbo refrigerator & Cooling & $3200 \mathrm{~kW}$ & 5.7 & 2 \\
\hline $\begin{array}{l}\text { HEX-01, } \\
\text { HEX-02 }\end{array}$ & $\begin{array}{l}\text { Heat exchanger } \\
\text { (For small load) }\end{array}$ & $\begin{array}{c}\begin{array}{c}\text { Exchange } \\
\text { heat quantity }\end{array}\end{array}$ & $1600 \mathrm{~kW}$ & - & 2 \\
\hline $\begin{array}{l}\text { HEX-03, } \\
\text { HEX-04 }\end{array}$ & Heat exchanger & $\begin{array}{c}\text { Exchange } \\
\text { heat quantity }\end{array}$ & $3200 \mathrm{~kW}$ & - & 2 \\
\hline \multirow[b]{2}{*}{ CT-1 } & \multirow{2}{*}{$\begin{array}{l}\text { Heat storage tank } \\
\text { (Chilled water) }\end{array}$} & Capacity & $684 \mathrm{~m}^{3}$ & - & \multirow[b]{2}{*}{1} \\
\hline & & $\begin{array}{c}\text { Heat storage } \\
\text { amount }\end{array}$ & $6363 \mathrm{kWh}$ & - & \\
\hline \multirow{2}{*}{ CHT-2 } & \multirow{2}{*}{$\begin{array}{c}\text { Heat storage tank } \\
\text { (Chilled / Hot water) }\end{array}$} & Capacity & $1020 \mathrm{~m}^{3}$ & - & \multirow[b]{2}{*}{1} \\
\hline & & $\begin{array}{c}\text { Heat storage } \\
\text { amount }\end{array}$ & $9488 \mathrm{kWh}$ & - & \\
\hline \multirow[b]{2}{*}{ CHT -3} & \multirow{2}{*}{$\begin{array}{l}\text { Heat storage tank } \\
\text { (Chilled / Hot water) }\end{array}$} & Capacity & $696 \mathrm{~m}^{3}$ & - & \multirow[b]{2}{*}{1} \\
\hline & & $\begin{array}{l}\text { Heat storage } \\
\text { amount }\end{array}$ & $6474 \mathrm{kWh}$ & - & \\
\hline
\end{tabular}

partial load is treated with the heat storage / release from the thermal storage tank, so the heat source machine is operated almost at the rated point. In addition, R-03 is a heat recovery-type heat pump that is in use in the winter since there is no heating load in summer. In 2015, the performance of each heat source machines of the East plant was almost operated at a rated point with high efficiency. The coefficient of performance (COP) of the East plant system was 1.45 (primary energy conversion) in 2015, which is the top-level value for DHC plants and exceeds the target design value of 1.3 or more. In this paper, COP of equipment is expressed as secondary 
energy conversion COP, and COP of plant is expressed as COP of primary conversion. The plan for the West plant followed the East plant, because the operating results of the East plant was a satisfactory. The West plant has two types of heat source machines: primary heat source machines (R-A01, R-A02, R-A03, R-A04,) connected to thermal storage tanks and secondary heat source machines (R-A05) which supply chilled water directly to consumers. Either R-A03 or R-A04 can serve a heat recovery-type heat source. However, in this study, we considered R-A03 and R-A04 as the cooling/heating switching-type and heat recovery-type heat source machine, respectively. These heat source machines have a larger capacity than R-03 in the East plant because the hotel in the West building has a larger heating load compared to the East building. Because R-A03 and R-A04 were adopted as generalpurpose heat source machines due to cost considerations, heat souse water is heat interchanged using a plate type heat exchanger. Shell and tube type heat exchanger (RHEX-A1) is separately provided because of the risk that pinholes may be produced from using river water in the plate heat exchanger. It is desirable to control both the East and West plants integrally, but it is difficult because it is necessary to perform great repair to control it integrally. At present, the operator inputs the direction and quantity of heat conduction, and it is carried out by heat interchange pump operation or valve opening which connects each plant, the upper limit of the heat amount is $3,887 \mathrm{~kW}$ at cooling and $2,791 \mathrm{~kW}$ at heating. The heat interchange amount is added / subtracted from the thermal load of the customer of eace area to calculate the thermal load that each plant shares, and based on that, the operation control of the heat source machine and the heat storage tank is performed for each plant.

\section{DHC system simulation model}

\section{Calculation flow}

Figure 3 is a flow diagram of the simulation model. The simulation model was created using Fortran 90/95. We referred to the characteristic expression of the past literature (Daniel R Clark 1985, Chiba T et al 1998) as a model of pumps, piping and valves. The actual values in 2015 for the thermal load of the East Plant and river water temperature were used as input data. Using the relationship between the design and measured values for the East Plant, the input thermal load of the West Plant was corrected for the thermal load design value of the West Plant, because it was not fully operated. Control of the heat interchange and the number of running equipments, such as heat source machines and heat exchangers, was determined based on the thermal loads of both plants. The characteristics of the heat source machine used the equipment characteristic diagram which made by the manufacturer, we created characteristic formula of load factor of the heat source machine and cooling water temperature were prepared. The opening rate of the valves and frequency inverters for the pumps were regulated through a PI controller based on the system conditions at the previous step. The flow rate at several points in the pipes was calculated by convergence calculation to ensure that the pressure distribution at each point is balanced. The heat interchange amont and direction were used as an input value, and when heat interchange is carried out, energy consumption of each plant was calculated that each plant is responsible for the load that adds or subtracts the heat interchange amount to the load of each area, the conditions of each heat source machine, heat exchanger, and thermal storage tank in each plant were assessed. The calculation interval is $1 \mathrm{~min}$. Since it is expected that the heat loss from the heat interchange pipe will also increase due to heat interchange between the plants, we have constructed a model to calculate the heat loss from the heat interchange pipe during heat interchange. We

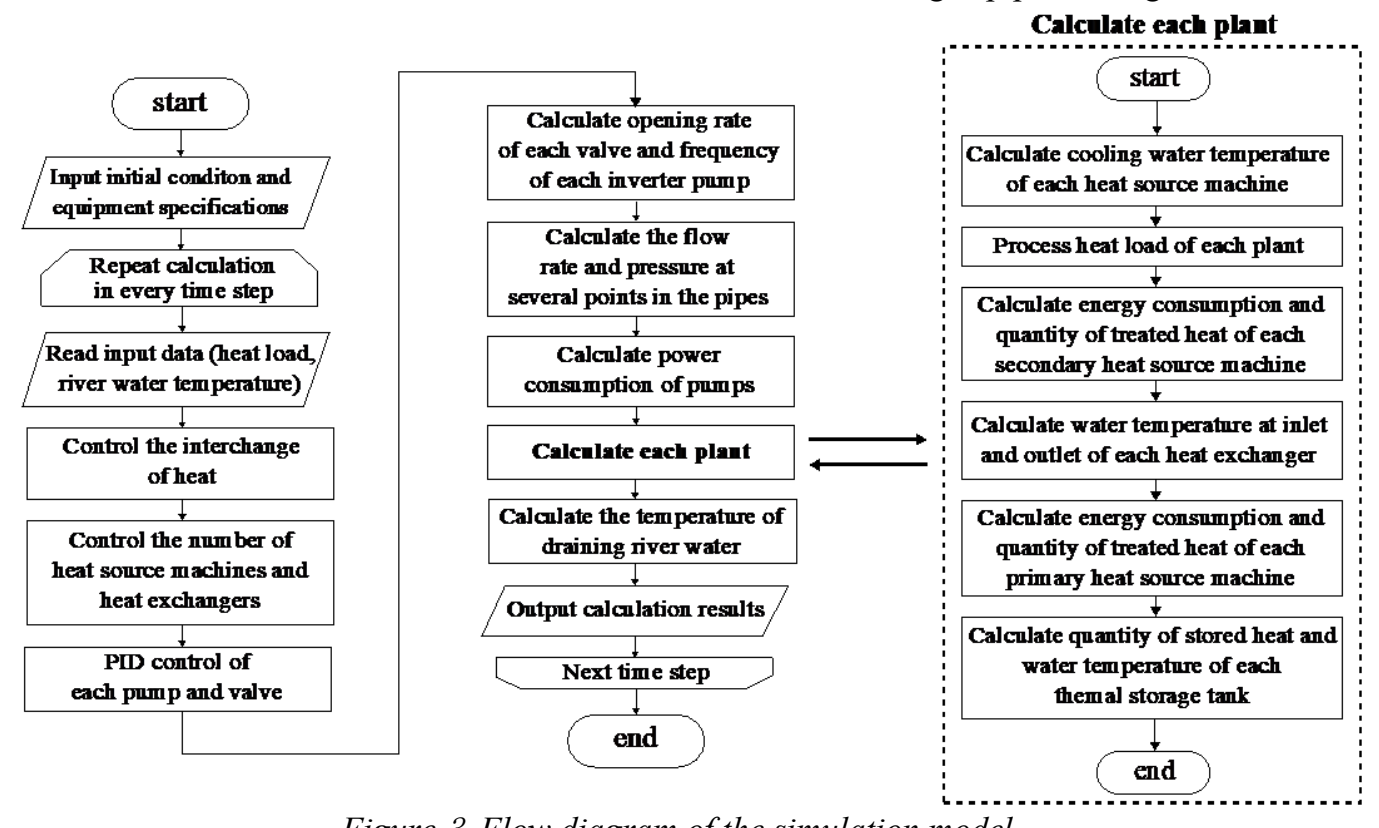

Figure 3. Flow diagram of the simulation model. 
calculated the heat loss in a steady state with the temperature and flow rate in the heat interchange pipe being the same as those of the heat interchange pipe inlet, calculated the temperature drop / rise due to heat loss while passing through a length of heat interchange pipe, and calculated the outlet temperature by additioning / subtracting the calculated temperature from the inlet temperature. Each physical property value of the circular pipe model of a target system, heat interchange pipe, and a design value are shown in Figure4.

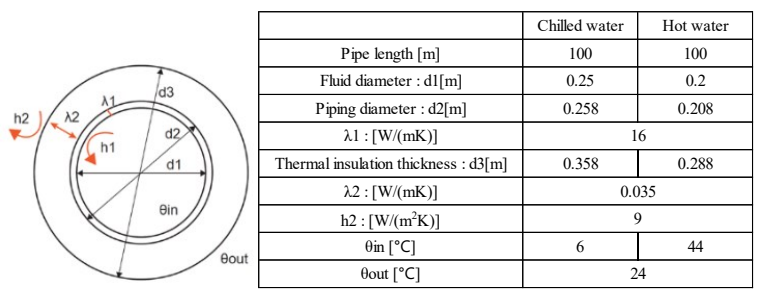

Figure 4. Specification of heat interchange pipe

$Q=k^{\prime} \pi l(\theta$ in $-\theta o u t)$

$k^{\prime}$ : Heat passing rate $[\mathrm{W} /(\mathrm{mK})], l:$ Pipe length $[\mathrm{m}]$, $\theta$ in : Fluid inlet temperature $\left[{ }^{\circ} \mathrm{C}\right]$, $\theta$ out : Piping ambient temperature $\left[{ }^{\circ} \mathrm{C}\right]$

$$
k^{\prime}=\frac{1}{\frac{1}{h 1 d 1}+\frac{1}{2} \Sigma \frac{1}{\lambda i} \ln \frac{d_{i+1}}{d_{i}}+\frac{1}{h 2 d_{n+1}}}
$$

$h 1$ : Fluid-side heat transfer coefficient $\left[\mathrm{W} /\left(\mathrm{m}^{2} \mathrm{~K}\right)\right]$, $d_{n}$ : Distance from the center to the surface of the target layer $[\mathrm{m}], \lambda i$ : Heat transfer coefficient of target layer $[\mathrm{W} /(\mathrm{mK})], h 2:$ Out-side heat transfer coefficient $\left[\mathrm{W} /\left(\mathrm{m}^{2} \mathrm{~K}\right)\right]$

$R e=\frac{V_{m} D_{h}}{v}$

$V_{m}:$ Flow speed $[\mathrm{m} / \mathrm{s}], \quad D_{h}:$ Hydraulic diameter $[\mathrm{m}]$ ( $\fallingdotseq$ Pipe diameter) $, v:$ kinematic coefficient of viscosity $\left[\mathrm{m}^{2} / \mathrm{s}\right]$

$$
\begin{aligned}
& N u=3.66+\frac{0.065(D / L) R_{e} P_{r}}{1+0.04\left\{(D / L) R_{e} P_{r}\right\}^{2 / 3}} \text { (Laminar) } \\
& N u=\frac{(f / 8)\left(R_{e}-1000\right) P_{r}}{1+12.7(f / 8)^{0.5}\left(P_{r}^{2 / 3}-1\right)} \text { (Turbulent) } \\
& \mathrm{h} 1=\frac{N u \lambda}{D h} \\
& f=\left(0.790 \ln R_{e}-1.64\right)^{-2}\left[3000<\operatorname{Re}<5 * 10^{6}\right] \\
& D: \text { Pipe diameter }[\mathrm{m}], \quad L: \text { Pipe length }[\mathrm{m}], P_{r}: \\
& \text { Prandtl number }, \quad \lambda: \text { Fluid thermal conductivity } \\
& {[\mathrm{W} /(\mathrm{mK})]}
\end{aligned}
$$

The amount of heat loss (the amount of heat passing) Q [W] from the fluid to the outside when the fluid passes through the circular pipe is expressed by the following equations (1) and (2). Since the heat interchange pipe is installed in the underground pit in the same space as the river water pipe, $\theta$ out was assumed to be the same as the river water temperature. The fluid-side heat transfer coefficient h1 [W / $\left.\left(\mathrm{m}^{2} \mathrm{~K}\right)\right]$ is considered to change with the flow velocity, and thereby the heat transfer coefficient also changes. Therefore, the fluid-side heat transfer coefficient h1 was calculated by the equations (3) to (5) for each flow velocity with respect to the heat transfer pipe of the target system. If $\operatorname{Re}$ (Reynolds number) $<3000$, it is discriminated as laminar flow, if $\mathrm{Re}>3000$, it is discriminated as turbulent flow. $\mathrm{Nu}$ (average Nusselt number) is determined from the state of the fluid. We calculated heat transfer rate and temperature change calculated from heat loss amount at $\theta$ out $=24{ }^{\circ} \mathrm{C}$ for each flow rate are shown in Figure 5. The heat transfer rate hardly changes with the flow rate when flow rate is around 2 to $5 \mathrm{~m}^{3} / \mathrm{min}$, which can be considered under normal operating conditions. This is the fluid-side heat transfer coefficient $h 1$ is on the order of the cube of 10 , so that the term bye $\mathrm{h} 1$ can be almost ignored. And temperature change is very small. Since the thermometer installed in the heat transfer tube shows an abnormal value (The magnitude relationship between the inlet and outlet temperature values of heat interchange pipe is reversed), it has not been possible to verify the actual temperature drop / rise.

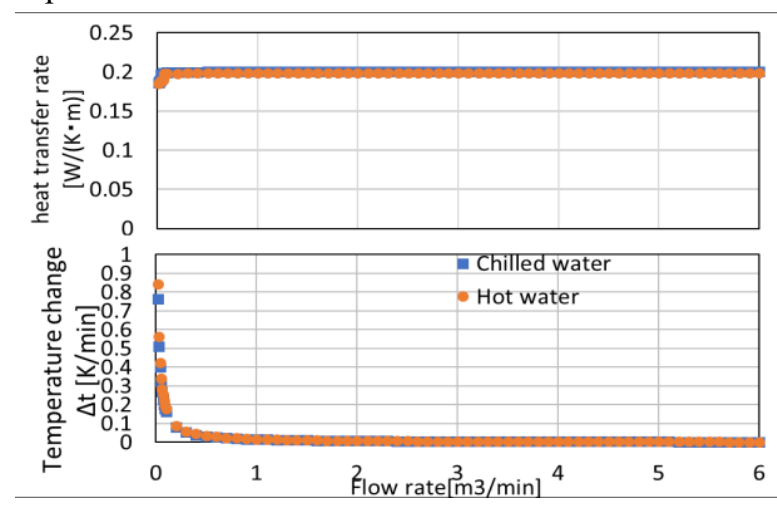

Figure 5. Heat transfer rate and temperature change

\section{Model validation}

Figure 6 shows the simulation results for the monthly COP of each plant during independent operations and the actual monthly COP values of the East Plant, and shows the simulation results and actual monthly COP of each heat source machine in the East Plant in 2015. Table 2 shows the simulation results for the efficiency of each heat source machine. A comparison of the simulation results for the East plant with the actual results showed good agreement. The slight difference in results was attributed to the decline in the efficiency of R-04 in the summer of 2015 by equipment trouble. R-3 had equipment trouble so the efficiency is also lower than in the simulation, but the effect on the whole plant was small because the capacity was small. A comparison of the simulation results for both plants showed that the system COP was almost equal in the summer or the East plant is somewhat better in the summer; the West plant is better in the winter. In the summer, the performance of each heat source machine of the West plant was higher because the West plant was newer (Compare machines of the same type, R-01,02 and RA-01,02; R-05,06 and RA-05). However, the efficiency of R-A03 was lower compared to other heat source machines that used river water directly as cooling water. This is because it exchanges heat with 

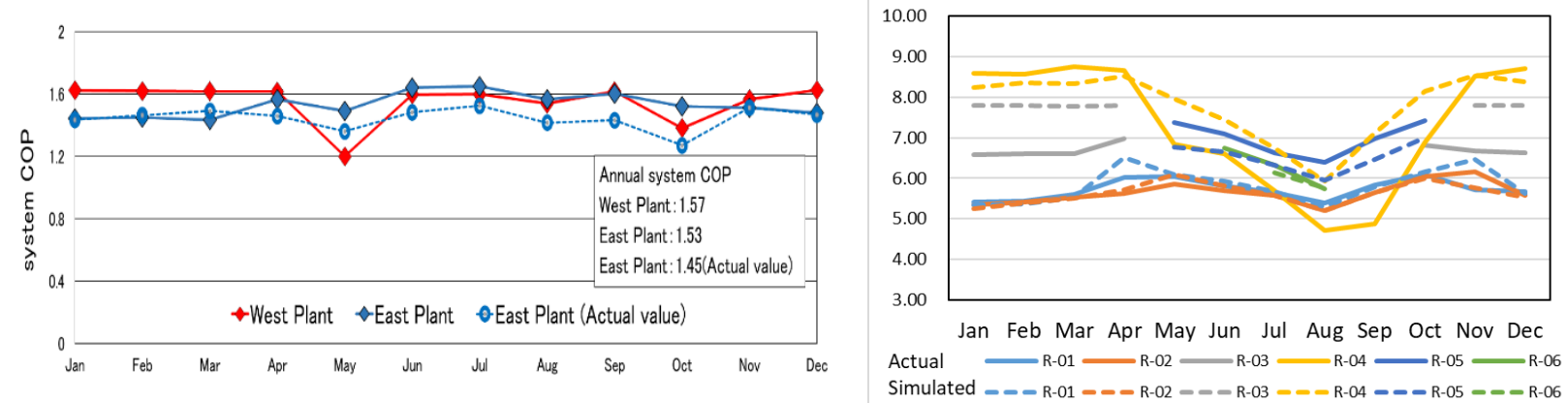

Figure 6. Simulation results of each plant and heat source machine in the east plant when independent operation and actual value of the East plant. (2015)

Table 2. Monthly COP of each heat source machine (Simulation results)

\begin{tabular}{|r|r|r|r|r|r|r|r|r|r|r|r|r|}
\hline & \multicolumn{1}{c|}{ Jan } & \multicolumn{1}{c|}{ Feb } & \multicolumn{1}{c|}{ Mar } & \multicolumn{1}{c|}{ Apr } & \multicolumn{1}{c|}{ May } & \multicolumn{1}{c|}{ Jun } & \multicolumn{1}{c|}{ Jul } & Aug & \multicolumn{1}{c|}{ Sep } & Oct & \multicolumn{1}{c|}{ Nov } & Dec \\
\hline R-A01 & 5.73 & 5.73 & 7.20 & - & 6.17 & 6.06 & 5.85 & 5.42 & 5.94 & 6.24 & 6.51 & 5.76 \\
\hline R-A02 & 5.64 & 5.70 & 5.82 & 5.87 & 6.03 & 5.82 & 5.72 & 5.38 & 5.78 & 5.93 & 5.95 & 5.81 \\
\hline R-A03 & 8.83 & 8.89 & 8.40 & 7.88 & 6.43 & 6.06 & 5.57 & 4.93 & 5.76 & 6.56 & 7.41 & 8.27 \\
\hline R-A04 & 7.90 & 7.89 & 7.87 & 7.82 & 0.08 & - & - & - & - & - & 7.77 & 7.89 \\
\hline R-A05 & - & - & - & - & - & 6.79 & 6.43 & 6.12 & 6.70 & 7.29 & 7.94 & - \\
\hline R-01 & 5.59 & 5.60 & 6.93 & 6.54 & 6.11 & 5.95 & 5.70 & 5.31 & 5.82 & 6.16 & 6.42 & 5.69 \\
\hline R-02 & 5.48 & 5.49 & 5.60 & 5.70 & 6.04 & 5.80 & 5.60 & 5.23 & 5.67 & 5.99 & 5.75 & 5.61 \\
\hline R-03 & 7.81 & 7.81 & 7.70 & 7.76 & - & - & - & - & - & - & 7.77 & 7.78 \\
\hline R-04 & 7.66 & 8.04 & 8.07 & 8.30 & 7.99 & 7.45 & 6.77 & 5.95 & 7.12 & 8.16 & 8.51 & 7.91 \\
\hline R-05 & - & - & - & 6.91 & 6.79 & 6.66 & 6.34 & 5.97 & 6.47 & 7.02 & - & - \\
\hline R-06 & - & - & - & - & - & - & 6.15 & 5.77 & - & - & - & - \\
\hline
\end{tabular}

river water via a separate heat exchanger, and the cooling water temperature became about $3{ }^{\circ} \mathrm{C}$ higher than the river water. In the winter, the efficiency of the heat source machine of the West plant was higher and the capacity of a heat source machine to perform efficient heat recovery operations larger in the West plant than in the East plant. As a result, the efficiency of the West plant is higher.

\section{Case study of heat interchange}

It is expected that heat interchange is more effective when the performance difference between sub-plants is large. We investigated total 24 cases (see Figure.7) for four patterns of performance degradation for East Plant (100\% (actual machine value), 70\%, 50\%, and 35\% (partial load characteristic is similar deformation)) and three patterns of thermal load amount difference in East Plant (100\% (actual value), $75 \%$, and $50 \%$ ) and two pattern of heat interchange (available or not). In addition, to investigate the effect of the difference in use of demand sides on

\begin{tabular}{|c|c|c|c|c|c|}
\hline \multicolumn{2}{|c|}{ Equipment efficiency } & \multicolumn{2}{|c|}{ Heat load } & \multicolumn{2}{|c|}{ Heat interchange } \\
\hline Case 1 & $100 \%$ & Case $\alpha$ & $100 \%$ & Case A & Not perform \\
\hline Case 2 & $70 \%$ & Case $\beta$ & $75 \%$ & Case B & Perform \\
\hline Case 3 & $50 \%$ & Case $\gamma$ & $50 \%$ & & \\
\hline Case 4 & $35 \%$ & & & & \\
\hline
\end{tabular}

$4 \times 3 \times 2=24$ cases

Heat loat patern

\begin{tabular}{|l|l|}
\hline Patern a & Mainly office (Current status) \\
\hline Patern b & Shopping center \\
\hline Patern c & Hospital \\
\hline
\end{tabular}

Figure. 7 Cases for examination effectiveness of heat interchange, we examined the three types of thermal loads of the West area of the mainly office of the current state, shopping-center, and hospital (see Figure.7). Thermal loads of shopping-center and hospitals is actual load data in the same region was used. Since the cooling peak load is an important factor for selecting the equipment, the similarity conversion was performed so that the peak of the actual load data becomes the same as the peak of the assumed thermal load in the West area. Considering the practicality of operation, we set the frequency of changing heat interchange setting twice a week on weekdays (Monday - Friday) and weekends (Saturday and Sunday). Heat interchange setting consists of three modes, mode 1 in which only independent operation is performed, mode 2 in which only cooperative operation is performed, and mode 3 in which these are combined (Figure.8). The heat interchange direction is 2 patterns of West Plant $\rightarrow$ East Plant, East Plant $\rightarrow$ West Plant. Set value of heat

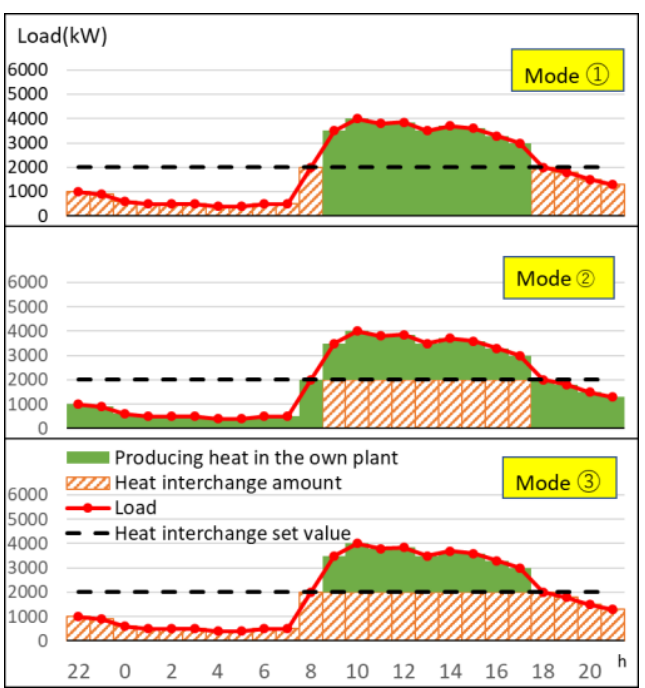

Figure. 8 Control image of heat interchange 
interchange amount is eight patterns, $12.5 \%, 25 \%, 37.5 \%$, $50 \%, 62.5 \%, 75 \%, 87.5 \%$ and $100 \%$ (the maximum amount of heat interchange). We selected the most efficient control protocol among 48 patterns for each case. The unit of the day is from 22:00 of the heat storage start time to $22: 00$ on the next day.

\section{Result and discussion}

\section{Current heat load pattern: Patern a}

- Plant characteristics without heat interchange (Case A)

The results of Case $\alpha$ are shown in Figure 9. The annual COP of West Plant is 1.586 in any case (Case 1 4), and it is displayed overlapping on the graph. The annual COP of the East Plant is 1.573 for Case 1 and 1.79 for Case 2, 0.924 for Case 3, 0.682 for Case 4, and the total COP for East and West is 1.580 to 0.989 . In Case 2, the results of Case $\alpha \sim \gamma$ are shown in Figure 10. The annual COP of the West Plant is unchanged from each case, and it is displayed overlapping on the graph. Even if the thermal load in the East area is variable (50\% to $100 \%)$, the COP of the plant in the East area is not big different from 1.145 to 1.209. It is thought that because the partial load corresponds to the heat storage / heat radiation from the thermal storage tank, the heat source machine is rated operation even if the thermal load is varied.

- Plant characteristics with heat interchange (Case B)

As an example, the results of comparison of heat interchange perform / not perform in Case $2 \beta$ are shown in Figures 11 to 12. In this case, heat interchange is performed from the West Plant which is highly efficient, to the East Plant. The efficiency of the West Plant improved by increasing the load burdened by the West Plant at the time of the cooling-heating switching time when the thermal load becomes the minimum, etc. Although the efficiency of the East Plant declines, since the load shared by the East Plant is small, the monthly COP is improved by $5.6 \%$ to $14.2 \%$ by heat interchange as a whole of $\mathrm{E}+\mathrm{W}$, and total annual COP increase $8.3 \%$ from 1.405 to 1.521 . The results compared with each heat source machine are shown in Figure 13. Efficiency of each equipment does not change greatly with or without heat interchange. The thermal load share ratio by each heat source machine is increased at the heat source machine in the West Plant. The cooling load in the East Plant became less burdens other than R-03 (heat recovery) and R-04 (Inverter turbo) which are high efficiency, and even in heating, heat burden other than R-03 (heat recovery) are reduced. At this case, the power consumption of the heat interchange pump is $0.24 \%$ of the whole plant and the heat loss from the heat interchange pipe is $0.22 \%$ of the heat transfer amount, which is slight. Table 3 summarizes the efficiency at the time of non-heat interchange and heat interchange in each case and the efficiency improvement rate by heat interchange in each case. In Case 1 where the difference in efficiency between plants is small, even if the load condition is changed, the COP improvement rate of the plant as a whole due to heat interchange is not as large as $2.1 \%$ to $2.3 \%$. In each case

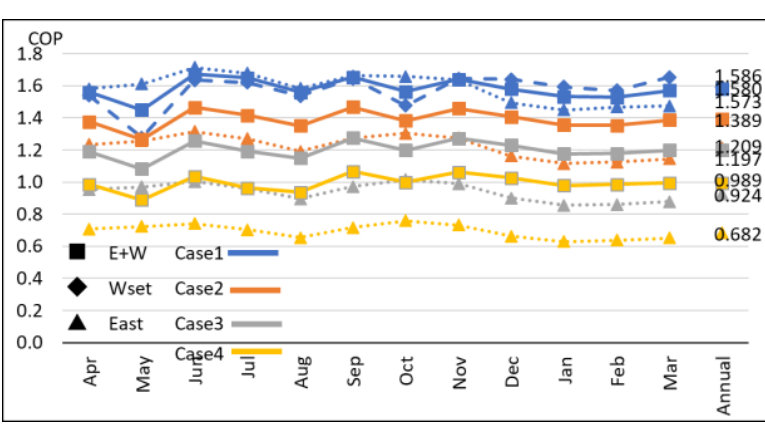

Figure.9 Monthly plant COP Case1 4

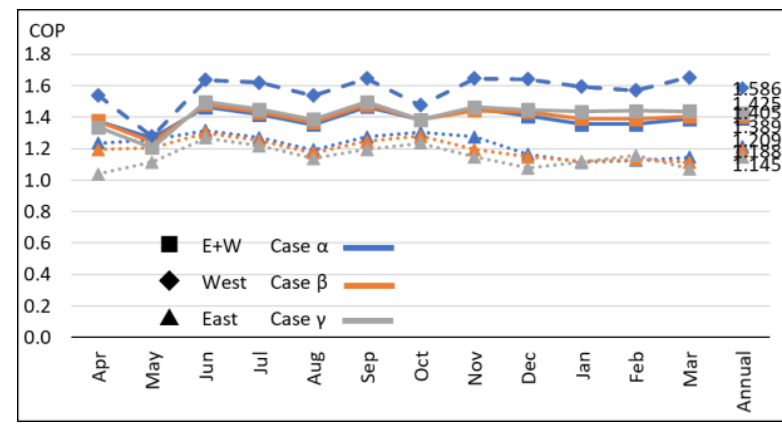

Figure.10 Monthly plant COP Case $\alpha \sim \gamma$

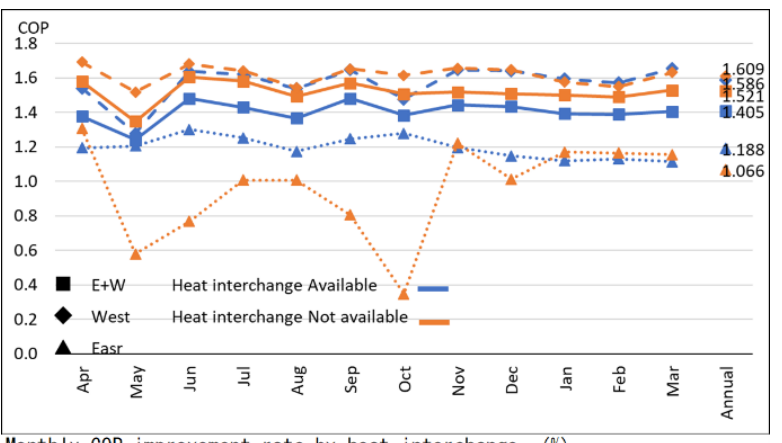

Monthly COP improvement rate by heat interchange (\%) \begin{tabular}{|c|c|c|c|c|c|c|c|c|c|c|c|c|}
\hline Apr & May & Jun & Jul & Aug & Sep & Oct & Nov & Dec & Jan & Feb & Mar & Annual \\
\hline 14.6 & 8.6 & 8.5 & 10.5 & 9.3 & 6.1 & 8.9 & 5.2 & 5.3 & 7.8 & 7.3 & 8.8 & 8.3 \\
\hline
\end{tabular}

Figure.11 COP difference by heat interchange

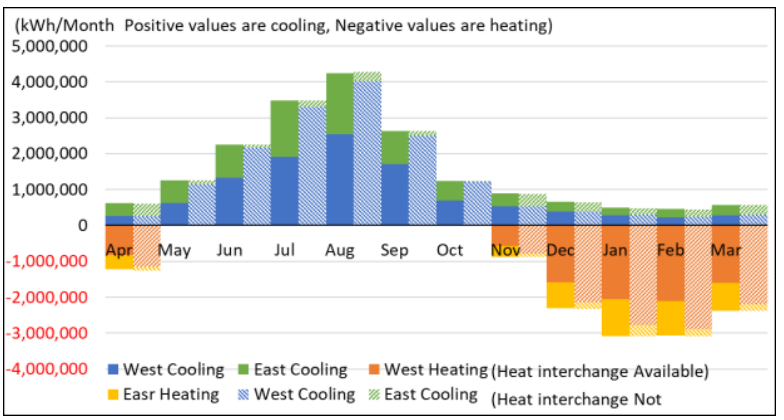

Figure.12 Heat generation difference

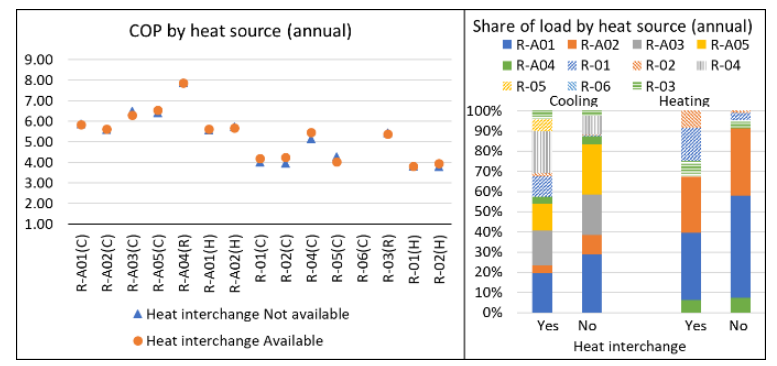

Figure.13 perating conditions of heat souse machine 
of Case 2 to Case 4, since the efficiency of the East Plant is low, whole efficiency improves by heat interchange from the West Plant to the East Plant, and the difference increases as the efficiency difference increases. As the thermal load on the heat receiving side decreases, the efficiency improvement rate due to heat interchange is decreased. This is because, as shown in Figure 14, as the thermal load on the heat receiving side decreases, the heat interchangeable amount decreases.

Table 4 summarizes the power consumption ratio of the heat interchange pump to the whole plant and the heat loss rate from the heat interchange pipe to the whole heat interchange amount in each case. In each case, power consumption rate of the heat interchange pump is $0.10 \%$ to $0.37 \%$, and the heat loss rate from the heat interchange pipe is $0.17 \%$ to $0.34 \%$, which is considerably lower than the efficiency improvement rate by heat interchange. In the case of heat interchange with the next block like the target case (piping length is about $100 \mathrm{~m}$ ), it is considered that the increase of the transportation power and the heat loss from the piping, which due to heat interchange are slight. But if the heat interchange piping gets longer, the transfer power and the heat loss become large and need to be considered.

\section{Different heat load pattern: Pattern b and c}

Next, assuming the case of heat interchange between buildings of different buildings, we examined by changing the load pattern of the West area. The thermal load pattern used the results of shopping-center and hospitals located in the neighbourhood. Since selection of equipment is often based on peak load, similarity transformation was performed so that the peak value of each data would be the peak value in the west area. Figure 15 shows the monthly thermal load for each building applications.

- Plant characteristics without heat interchange (Case $1 \alpha$ A)

The examination results are shown in Figure 16. In the summer, there is no big difference in efficiency between each case, but efficiency of the shopping-center in winter is low. This is because the air-conditioning of the shopping-center is exclusively for cooling, operation of the heat recovery machine can not be performed in the winter, and the cooling load is also very small. Also, in the case of the current office load, the efficiency tends to be somewhat lower in the middle term. This is thought to be because the heating load is not so large, and the cooling load is very small. From these trends, it is thought that lengthening the operation time of the heat recovery machine, avoiding operation with a very small load by putting a load on one side by heat interchange will lead to an improvement in the whole efficiency.

- Improvement due to heat interchange

Table 5 summarizes the efficiency at the time of non-heat interchange and heat interchange in each case and the efficiency improvement rate by heat interchange in each case, when the thermal load pattern is changed to the office and the hospital. The plant COP has a higher value
Table3.Plant COP and improvement rate in each case

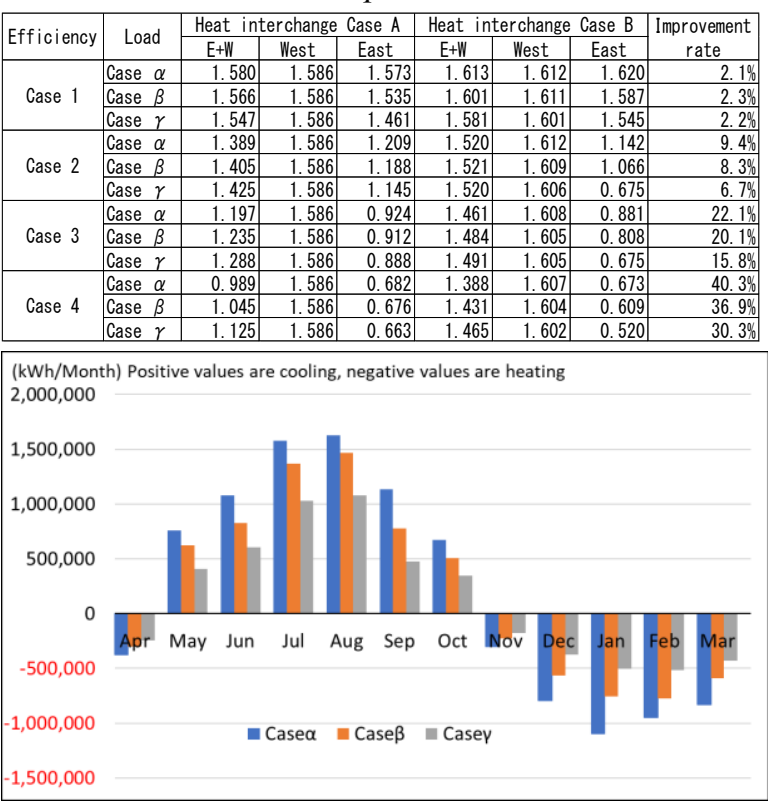

Figure.14 Monthly heat interchange amount

Table4. The power ratio of the heat interchange pump and the heat loss rate from the heat interchange pipe

\begin{tabular}{|c|c|c|c|c|c|}
\hline \multirow[b]{2}{*}{ Efficiency } & \multirow[b]{2}{*}{ Load } & \multirow{2}{*}{$\begin{array}{l}\text { Heat interchange } \\
\text { pump power } \\
\text { consumption rate }\end{array}$} & \multicolumn{3}{|c|}{ Heat loss rate } \\
\hline & & & hot water & Chilled water & Total \\
\hline \multirow{3}{*}{ Case 1} & Case $\alpha$ & $0.12 \%$ & $0.39 \%$ & $0.15 \%$ & $0.24 \pi$ \\
\hline & Case $\beta$ & $0.11 \%$ & $0.54 \%$ & $0.17 \%$ & 0.28 \\
\hline & Case $\gamma$ & $0.10 \%$ & $0.81 \%$ & $0.18 \%$ & 0.340 \\
\hline \multirow{3}{*}{ Case 2} & Case $\alpha$ & $0.32 \%$ & $0.30 \%$ & $0.11 \%$ & 0.18 \\
\hline & Case $\beta$ & $0.24 \%$ & $0.38 \%$ & $0.13 \%$ & 0.22 \\
\hline & Case $\gamma$ & $0.14 \%$ & $0.56 \%$ & $0.19 \%$ & 0.32 \\
\hline \multirow{3}{*}{ Case 3} & Case $\alpha$ & $0.37 \%$ & $0.28 \%$ & $0.10 \%$ & 0.179 \\
\hline & Case $\beta$ & $0.28 \%$ & $0.36 \%$ & $0.13 \%$ & 0.22 \\
\hline & Case $\gamma$ & $0.15 \%$ & $0.53 \%$ & $0.19 \%$ & 0.32 \\
\hline \multirow{3}{*}{ Case 4} & Case $\alpha$ & $0.37 \%$ & $0.27 \%$ & $0.10 \%$ & 0.179 \\
\hline & Case $\beta$ & $0.29 \%$ & $0.34 \%$ & $0.13 \%$ & 0.218 \\
\hline & Case $\gamma$ & $0.16 \%$ & $0.50 \%$ & $0.19 \%$ & $0.31 \%$ \\
\hline
\end{tabular}

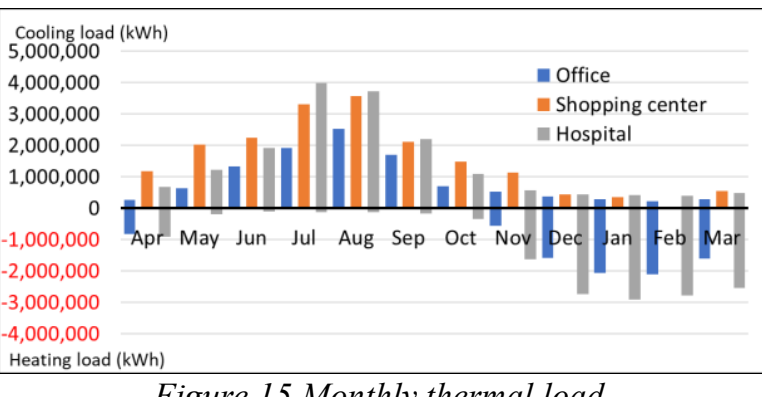

Figure.15 Monthly thermal load

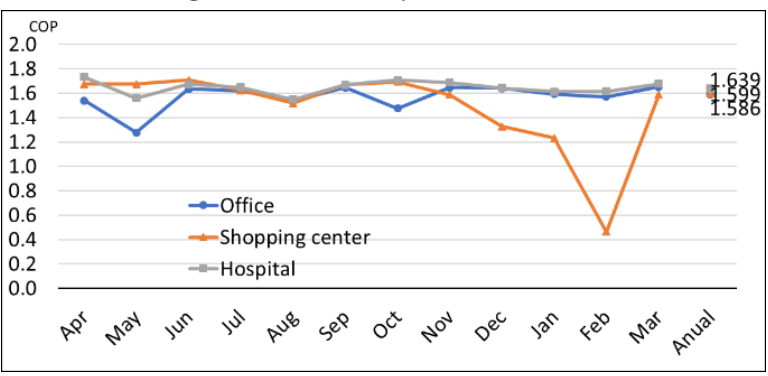

Figure.16 COP difference by thermal load form

in the case either in the case of thermal interchange or not. This is thought to be because the heating load of the hospital has a large and the heating load occurs in the summer, so the heat recovery machine operates effectively. The Plant COP was higher in the case of the 
thermal load of the hospital, when perform heat interchange. But the plant COP when not perform heat interchange was also high, so the efficiency improvement rate by heat interchange was low. As an example, the results of comparison of heat interchange perform / not perform in Case $2 \alpha$, when thermal load of the west area is hospital, shows in Figures 17 to 18. Heat interchange is performed from the West Plant, which is highly efficient, to the East Plant, same as pattern a. Although the efficiency of the East Plant declines, since the load burdened by the East Plant is small, the monthly COP is improved by heat interchange as a whole of $\mathrm{E}+\mathrm{W}$.

Table5. Plant COP and improvement rate in each

case

\begin{tabular}{|c|c|c|c|c|c|c|r|r|}
\hline \multirow{2}{*}{ Efficiency } & Heat load & \multicolumn{2}{|c|}{ Heat interchange Case A } & \multicolumn{3}{|c|}{ Heat interchange Case B } & Improvement \\
& patern & E+W & West & East & E+W & West & East & rate \\
\hline \multirow{2}{*}{ Case 1 } & Patern a & 1.580 & 1.586 & 1.573 & 1.613 & 1.612 & 1.620 & $2.1 \%$ \\
\cline { 2 - 9 } & Patern c & 1.618 & 1.639 & 1.573 & 1.643 & 1.657 & 1.618 & $1.5 \%$ \\
\hline \multirow{2}{*}{ Case 2 } & Patern a & 1.389 & 1.586 & 1.209 & 1.520 & 1.612 & 1.142 & $9.4 \%$ \\
\cline { 2 - 9 } & Patern c & 1.464 & 1.639 & 1.209 & 1.549 & 1.629 & 1.154 & $5.8 \%$ \\
\hline \multirow{2}{*}{ Case 3 } & Patern a & 1.197 & 1.586 & 0.924 & 1.461 & 1.608 & 0.881 & $22.1 \%$ \\
\cline { 2 - 8 } & Patern c & 1.301 & 1.639 & 0.924 & 1.495 & 1.623 & 0.881 & $14.9 \%$ \\
\hline
\end{tabular}

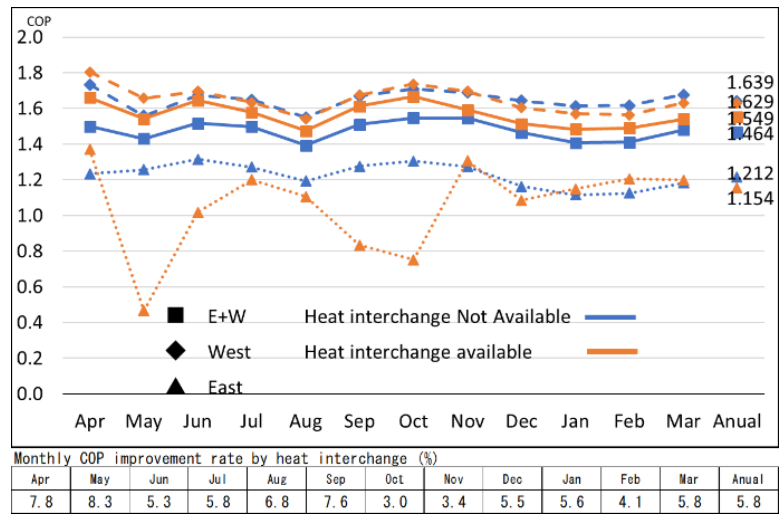

Figure.17 COP difference by heat interchange

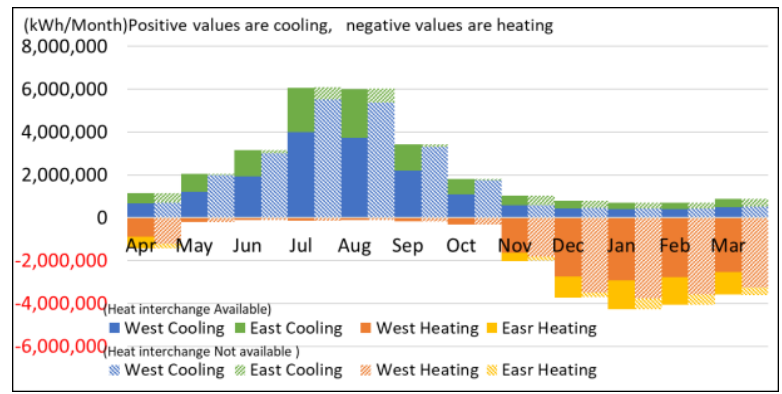

Figure.18 Heat generation difference by heat

interchange

\section{Conclusion and implications}

Conditions for promoting effective heat interchange between sub-plants in DHC system were investigated using simulation. The targeted system was a best practice, and the efficiency improvement effect by heat interchange was small in the actual plant. However, when there is a difference in efficiency between plants, it has been found that efficiency can be improved by approximately 10 to $40 \%$ if heat interchange is performed from higher efficiency plant to lower efficiency plant. In the target plant, the increase of the transport power and the increase of the heat loss are slight because the distance between plants is not so long, so the heat interchange was effective for improving the plant COP. It was also found that by performing the heat interchange, it is possible to increase the operation of the heat recovery machine and to avoid the extremely low load operation, leading to the improvement of whole efficiency. In addition, the tendency is similar for the case where the use of the building is different, it is effective to improve the plant COP by increasing the operation of the heat recovery machine and avoiding the extremely low load operation. In the future, when the partial load characteristic of the plant is bad, such as when there is no heat storage tank, when the distance of the heat conduit pipe is more longer, when the maximum heat conduction amount is variable, etc. we will consider the conditions under which heat interchange is effective and the control method at that time in various cases. In addition, even when the number of plants increases, using the heat transfer amount and direction as input values, the flow rate at several points in the pipes will be calculated by convergence calculation to ensure that the pressure distribution at each point is balanced, and we will be able to calculate the energy consumption of each plant. Using this simulation, performance verification of the system of the target area will be continued, and furthermore, we plan to investigate efficient system configuration as a whole area when DHC area is expanded or when equipment of plant is updated.

\section{References}

Daniel R. Clark. (1985). HVACSIM+ Building Systems and Equipment Simulation Program Reference Manual, NBSIR 84-2996.

Nishiyama M, Sumiyoshi D, and Akashi Y. (2015). Initial Commissioning of Heating and Cooling Plant System by Simulation - The meaning and effect of a system simulation in the design step, Transactions of SHASE, No 205, pp 27-35.

Chiba T, Iguchi Y, and Watanabe H. (1998). Control Characteristics of Piping Systems and Air Duct Systems, Journal of SHASE, Vol 72, pp 391-397.

Kobayashi T, Amemiya S, Hoshida T, and Okumiya M. (2012). Study on Operation of Area Energy System that Interchanges Energy among Multiple Heat Source Plants - Part1 Method of Simulation and Basic Case Study, Transactions of SHASE, No 183, pp 37-46.

Kawasaki Y, Kitora H, Akashi Y, and Lim J (2016). Optimal operation of multiple district heating and cooling systems through mutual interchange of heat. Proceedings from ASIM 2016. Jeju (Korea), 27-29 Nov.2016. 